\title{
EFS-ADA Lentiviral Vector-transduced CD34-positive Autologous Lymphocytes
}

National Cancer Institute

\section{Source}

National Cancer Institute. EFS-ADA Lentiviral Vector-transduced CD34-positive

Autologous Lymphocytes. NCI Thesaurus. Code C113438.

A preparation of autologous, CD34-positive stem/progenitor cells transduced with a lentrivral vector encoding the human adenosine deaminase (ADA) gene under the control of the human elongation factor alpha short promoter (EFS), with potential to restore ADA expression and function. Autologous hematopoietic CD34+ cells are isolated from the patient's own bone marrow, peripheral blood or cord blood, and transduced with the EFS-ADA lentiviral vector ex vivo. Upon re-infusion of the EFS-ADA vector-transduced lymphocytes back into the patient, these cells may both restore ADA activity and prevent severe combined immunodeficiency (SCID) due to ADA deficiency. ADA, an enzyme that catalyzes the deamination of adenosine to inosine, plays a key role in the development and functioning of the immune system. 